\title{
Ações Coletivas no Agronegócio: uma análise da produção científica no Brasil a partir de teses e dissertações
}

$(1998-2012)^{1}$

\author{
Keila Raquel Wenningkamp² e Carla Maria Schmidt ${ }^{3}$
}

Resumo: Este estudo, que é parte de uma dissertação de mestrado, teve como objetivo compreender a produção científica no Brasil sobre ações coletivas no agronegócio, a partir de teses e dissertações defendidas entre os anos 1998 e 2012. Para esta pesquisa, ações coletivas são estruturas de governança caracterizadas pela atuação conjunta de indivíduos e/ou firmas que unem esforços para atingir objetivos comuns. Em termos metodológicos, este trabalho caracterizou-se como um estudo sobre o estado da arte e uma pesquisa bibliométrica, com abordagem quantitativo-qualitativa. Como principais resultados, constatou-se a existência de pesquisas na área de ações coletivas no agronegócio. Além disso, esses estudos têm aumentado nos últimos anos, porém, em número ainda pequeno se forem consideradas a recorrência e a importância dessas estruturas para o agronegócio. Quanto às principais características encontradas nas teses e dissertações, observou-se que, em sua maioria, se constituem de estudos empíricos e focam modelos sob a forma de cooperativas, associações, redes e de APLs/clusters/aglomerados. Chegou-se à conclusão de que a agropecuária foi o segmento mais pesquisado nos estudos de caso e que as regiões Sul e Sudeste concentram tanto a maior parte dos estudos quanto a maioria das formas coletivas estudadas.

Palavras-chaves: Ações coletivas; Agronegócio; Estado da arte; Bibliometria.

Abstract: This study is a result of the master dissertation that had the aim to understand the Brazilian scientific production about collective actions in agribusiness, found in dissertations (master and doctorate levels) from 1998 to 2012. For this research, collective actions are governance structures characterized by joint action of individuals or firms that join efforts for common goals. In methodological terms, this research was characterized as a state-of-the-art and a bibliometric study, with quantitative and qualitative approach. Based on the results, the existence of research in the area of collective actions in agribusiness was

1. Data de submissão: 16 de março de 2016. Data de aceite: 28 de março de 2016.

2. Universidade Estadual do Oeste do Paraná. Toledo, Paraná, Brasil. E-mail: sebkeila@hotmail.com

3. Universidade Estadual do Oeste do Paraná. Toledo, Paraná, Brasil. E-mail: carlamariaschmidt@hotmail.com.br 
found. Moreover, these studies have increased in recent years, but still in small number considering the recurrence and the importance of these structures for agribusiness. Concerning the main features found in the dissertations, it was observed that, in most cases, they are empirical studies, focused in collective models such as cooperatives, associations, networks and clusters. The results indicate that the agricultural segment was the most researched in the case studies and that the South and Southeast regions in Brazil concentrate both most of the studies and of the collective forms studied.

Key-words: Collective actions; Agribusiness; State-of-the-art; Bibliometrics.

Classificação JEL: Q13 - Agricultural markets and Marketing; Cooperatives; Agribusiness.

DOI - http://dx.doi.org/10.1590/1234-56781806-94790540302

\section{Introdução}

Nas últimas décadas, as organizações têm se deparado com expressivas mudanças de ordem política, econômica e social, geradas por forças de um mercado globalizado e marcado pela revolução tecnológica, pela concorrência acirrada, dentre outros aspectos. Diante dessa conjuntura, os agentes têm desenvolvido novas formas de governança baseadas na interação, na coletividade e na cooperação, a fim de se tornarem mais competitivos. Trata-se de formas complexas ou híbridas de governança, que estão emergindo em resposta a um contíguo de diferentes transações realizadas de maneira conjunta e simultânea, transações essas que as outras estruturas de governança, como o mercado e a hierarquia, não conseguem mais responder (AUSTIN, 2001; MÉNARD, 2004; SANDLER, 2004).

Assim, essas estruturas complexas surgem em razão de que ações isoladas e individuais muitas vezes não dispõem de todos os recursos e condições necessárias para atender as atuais demandas por inovação, variedade e diferenciação, exigindo a formação de ações coletivas entre indivíduos e organizações para a promoção de tais resultados de maneira mais eficiente. Para Austin (2001), as organizações dificilmente conseguem obter desempenho econômico sozinhas e precisam de cooperação, característica que marca o século XXI como a era das alianças. Ménard e Klein (2004) também mencionam o crescente número de casos de relacionamentos interorganizacionais, apontando essas estruturas de governança como uma das maiores tendências nos Estados Unidos, na Europa e no mundo em desenvolvimento. Diante disso, o que se entende é que, atualmente, há uma presença cada vez maior de parcerias entre indivíduos e organizações, caracterizando novas formas de negociação, baseadas em ações coletivas, as quais envolvem as mais diversas regiões e setores da economia.

Em relação aos setores econômicos, Ménard (2004) e Zylbersztajn (2005, 2010) apontam que o agronegócio, em seus variados Sistemas Agroindustriais (SAGs), tem sido fortemente permeado pela presença dessas estruturas complexas de governança sob a forma de redes, supply chain systems, netchains, clusters, arranjos produtivos locais (APLs), marcas coletivas, parcerias, alianças, sistemas de cadeia de suprimento, cooperativas, sindicatos, associações e empreendedorismo coletivo. Ademais, Ménard e Klein (2004) já citavam que existe um crescente interesse no estudo de ações coletivas em redes agroindustriais, principalmente na Europa, considerando que vários novos periódicos, como, por exemplo, Supply Chain Management, Journal on Chain and Science Network e Social Networking, têm destinado espaços consideráveis a essas questões.

Nesse sentido, Ménard (2004) aponta que, até meados da década de 1980, poucos estudos 
tinham sido publicados sobre as formas complexas de governança baseadas em ações coletivas, mas que, a partir de 1990, estudos nessa área começaram a ocorrer com maior frequência, provavelmente buscando respostas a uma nova realidade que surgia nos SAGs: formas de coordenação e organização caracterizadas pela coletividade, complementaridade e cooperação entre indivíduos e firmas. Contudo, até o momento, não foram encontrados estudos que apresentem uma compilação dos achados científico-empíricos na temática de ações coletivas no agronegócio.

Em face dessa problemática, com o intuito de preencher tal lacuna e de colaborar com a discussão sobre ações coletivas no agronegócio é que surge o interesse de realizar este estudo sobre a produção científica existente no referido campo. Dessa forma, o objetivo deste estudo é o de compreender a produção científica no Brasil sobre ações coletivas no agronegócio, a partir da análise de teses e dissertações defendidas entre 1998 e 2012. Para atingi-lo, alguns objetivos específicos foram estabelecidos:

a) descrever os estudos desenvolvidos no campo das ações coletivas no agronegócio;

b) investigar os aspectos teórico-empírico-metodológicos que fundamentam as teses e dissertações sobre ações coletivas no agronegócio;

c) mapear a concentração geográfica das teses e dissertações encontradas na temática e, também, a localização dos objetos de investigação desses estudos empíricos.

Assim, para melhor organizar este estudo, ele se subdivide em outras quatro seções centrais, além desta introdução. Na seção dois são abordados os aspectos teóricos do estudo, envolvendo, inicialmente, breves apontamentos sobre ações coletivas no agronegócio e, posteriormente, alguns aspectos sobre a importância de estudos sobre o estado da arte; na três, são apresentados os procedimentos metodológicos do estudo; na quatro são analisados e interpretados os dados coletados; e, na seção cinco, são tecidas algumas conclusões e considerações finais.

\section{Fundamentação teórica}

O agronegócio tem sido marcado, especialmente a partir de 1990, por estruturas complexas de governança, muitas vezes sob a forma de ações coletivas (MÉNARD, 2004; ZYLBERSZTAJN, $2005,2010)$. Essas ações coletivas, segundo Olson (1999), podem ser caracterizadas pela união de indivíduos ou firmas que possuem objetivos comuns e que buscam agir de forma conjunta e coordenada para alcançar tais objetivos. Sandler (2004) complementa que essas formas de coordenação envolvem interações estratégicas em que as escolhas de um indivíduo ou de uma firma (e as suas consequências) influenciam e são influenciadas umas pelas outras. Nesse contexto, entende-se que diferentes formatos de ações coletivas estão presentes nos SAGs, tais como: redes, cooperativismo, associativismo, clusters, APLs e aglomerados.

Em relação às redes, Zylbersztajn e Farina (2006) as caracterizam como:

a) arranjos institucionais complexos interfirmas, destinados a coordenar as operações, a fim de criar e capturar valor;

b) as transações ocorrem vertical e horizontalmente;

c) envolvem múltiplos agentes e vários períodos devem ser considerados;

d) o papel da confiança e das regras informais é potencialmente relevante, bem como existem contratos relacionais e dependência recíproca;

e) as estratégias são definidas em conjunto, com base na expectativa de ganhos mútuos e mecanismos de resolução de conflitos são projetados.

Já no que tange ao cooperativismo e ao associativismo, essas são estruturas que intermediam as atividades e as economias particulares dos associados/cooperados, por um lado, e o mercado, por outro (BIALOSKORKI NETO, 2000; SERVIÇO BRASILEIRO DE APOIO ÀS MICRO E PEQUENAS EMPRESAS - SEBRAE, 2009). A diferença entre as duas está na natureza dos dois 
processos, segundo Sebrae (2009), uma vez que as associações possuem como finalidade a promoção de assistência social, educacional e cultural, e as cooperativas envolvem a viabilização dos negócios produtivos dos cooperados junto ao mercado, tendo finalidade comercial.

Por sua vez, os clusters, os arranjos produtivos locais e os aglomerados, apesar de suas singularidades, neste estudo são tratados como sinônimos. Isso porque, conforme descrição dada por autores como Porter (1999) e a Rede de Pesquisa em Sistemas e Arranjos Produtivos e Inovativos Locais - Redesist (2014), esses conceitos possuem características similares, tais como: a proximidade geográfica, a realização de atividades correlatas, a presença simultânea de cooperação e de competição.

Essas e outras estruturas de governança coletivas têm se tornado objeto de estudo de várias pesquisas (MÉNARD, 2004), muitas delas buscando entender a sua importância para os atores envolvidos e para a sociedade, bem como os possíveis desafios existentes para a sua manutenção. Entre essas pesquisas, pode ser citada a de Schmidt et al. (2015), que buscou identificar vantagens e dificuldades de uma ação coletiva no turismo rural. Essa pesquisa concluiu que tais formas de coordenação podem resultar em diferentes ganhos (econômicos, sociais, culturais, psicológicos e ambientais), mas, justamente por serem estruturas complexas, também apresentam desafios, como é o caso da presença de indivíduos caronas e da ausência de liderança.

Feitas essas breves considerações sobre as ações coletivas em sistemas agroindustriais, torna-se relevante abordar aspectos sobre as pesquisas denominadas de estudos do estado da arte, já que isso embasa o principal objetivo deste trabalho.

\subsection{Estudos do estado da arte}

Nas últimas décadas, o número de pesquisas denominadas de estado da arte ou estado do conhecimento tem aumentado significativamente no Brasil e no mundo (FERREIRA, 2002).
Mas o que são estudos do estado da arte e por que realizá-los?

Conforme Ferreira (2002), estudos do estado da arte geralmente discutem e mapeiam a produção científica em uma temática específica, apresentando quais aspectos vêm sendo destacados, quais dimensões caracterizam determinada área e em que condições a produção acadêmica está sendo realizada. Com relação a esse aspecto, Antonello (2002) cita que "uma das condutas científicas necessárias ao desenvolvimento de novos campos de pesquisa refere-se à permanente 'vigilância epistemológica' sobre a própria produção" (p. 1). Isso quer dizer que análises permanentes devem ser feitas no sentido de conhecer o estado do conhecimento de uma temática específica e demonstrá-lo à comunidade científica.

Quanto uma definição sucinta, estado da arte é a compreensão do conhecimento em um tema particular, em um período predeterminado, a partir de sua sistematização e análise, o que se torna importante para toda e qualquer área (TEIXEIRA, 2006). Quem destaca essa importância é Momm (2009), quando afirma que estudos sobre a produção científica em uma determinada área são imprescindíveis, pois contribuem com a evolução da temática estudada, com o aprofundamento do conhecimento científico, servindo e auxiliando, também, para tomada de decisões sobre o referido campo. Além disso, a autora afirma que a análise do conhecimento científico pode contribuir para o entendimento não apenas de aspectos científicos, mas, também, de características políticas, socioeconômicas e culturais. Nesse mesmo sentido, Macias-Chapula (1998) já dizia que revisões de políticas científicas em uma determinada área dificilmente ocorreriam se não fossem os estudos sobre a produção do conhecimento científico da mesma.

Segundo Ferreira (2002), os pesquisadores que realizam estudos sobre o estado da arte em determinado campo são motivados pelo desafio de conhecer o que já foi produzido cientificamente, de forma a compilar tais pesquisas, que se avolumam rapidamente e cada vez mais. Dessa forma, "todos esses pesquisadores trazem 
em comum a opção metodológica, por se constituírem pesquisas de levantamento e de avaliação do conhecimento sobre determinado tema" (FERREIRA, 2002, p. 259).

Ferreira (2002) também argumenta que os pesquisadores do estado do conhecimento podem seguir dois diferentes procedimentos para a análise da produção científica:

1. quantificar e identificar a produção científica já existente, localizando-a no tempo e no espaço;

2. inventariar a produção científica, caracterizando-a em termos de objeto e modo/ forma.

No que tange ao primeiro momento, esse seria aquele em que o pesquisador interage com o material científico existente, de forma a fazer a quantificação, a identificação de dados bibliográficos e o mapeamento da produção em determinado período (em anos, locais e áreas). $\mathrm{Ou}$ seja, respondem-se perguntas relacionadas a "quando" e a "onde" ocorre a produção científica, realizando-se uma sistematização do conhecimento produzido, com base em dados considerados mais objetivos e concretos. A partir disso, é possível revelar o histórico e possível amadurecimento de linhas de pesquisa, bem como os períodos em que a produção científica cresce e se espessa, os pesquisadores e os autores envolvidos e a diversificação dos locais de produção do conhecimento. Ainda incluído nesse primeiro momento, podem ser citados os indicadores bibliométricos, uma vez que Macias-Chapula (1998) já afirmava que em qualquer estudo que se refere à produção científica de uma determinada ciência, indicadores bibliométricos são essenciais. De acordo com Pritchard (1969), a bibliometria é usada para quantificar os processos de comunicação escrita. Dito de outra forma, trata-se do estudo dos aspectos quantitativos da produção científica em determinada área, da disseminação e do uso das informações registradas (MACIASCHAPULA, 1998). Araújo (2006) complementa essa colocação, dizendo que o estudo bibliométrico se refere à aplicação de técnicas estatísticas e matemáticas para descrever aspectos da literatura, caracterizando-se, assim, como uma análise quantitativa da informação.

Inicialmente, essa técnica foi utilizada para a medida de livros, mas, com o passar do tempo, começou a ser utilizada para o estudo de outras formas de publicações, tais como artigos de periódicos, dissertações, teses e outros tipos de documentos, como produtividade de autores e estudo de citações (ARAÚJO, 2006). Essa metodologia permite a:

identificação e descrição de uma série de padrões na produção do conhecimento científico. Com os dados retirados das citações pode-se descobrir: autores mais citados, autores mais produtivos, elite de pesquisa, frente de pesquisa, fator de impacto dos autores, procedência geográfica e/ou institucional dos autores mais influentes em um determinado campo de pesquisa; tipo de documento mais utilizado, idade média da literatura utilizada, obsolescência da literatura, procedência geográfica e/ ou institucional da bibliografia utilizada; periódicos mais citados, "core" de periódicos que compõem um campo (ARAÚJO, 2006, p. 18-19).

Percebe-se que indicadores bibliométricos complementam e auxiliam na determinação dos primeiros aspectos a serem analisados sobre o conhecimento científico, principalmente no que se refere à quantificação da produção, à localização geográfica, à especificação temporal e à caracterização dos autores. Assim, esses indicadores são fundamentais à análise da produção científica de uma área específica, pois possibilitam compreender os procedimentos iniciais a serem seguidos nos estudos do estado da arte, conforme apontado por Ferreira (2002).

Já em relação ao segundo momento, Ferreira (2002) afirma que "o pesquisador se pergunta sobre a possibilidade de inventariar essa produção, imaginando tendências, ênfases, escolhas metodológicas e teóricas" (p. 265). Em outras palavras, nesse passo o pesquisador busca responder, além das perguntas sobre "quando" e "onde", questões que se referem ao objeto e ao modo, ou 
seja, "o quê" e "como" os trabalhos foram produzidos cientificamente em uma determinada área.

Nesse segundo momento, os dados não são tidos como objetivos e concretos, exigindo uma leitura mais profunda e completa do material que está sendo consultado. É nesse momento que os pesquisadores podem enfrentar várias dificuldades como, por exemplo: a necessidade de leitura integral de parte ou partes do trabalho; a falta de organização interna, de modo que seja difícil a classificação do estudo em determinado tema ou teoria; conflitos e divergências entre objetivos traçados e resultados alcançados; e falhas estruturais e metodológicas, decorrentes muitas vezes pelo curto período de tempo para a realização da pesquisa, principalmente nos casos de teses e dissertações (FERREIRA, 2002; TEIXEIRA, 2006).

De acordo com o exposto até aqui, percebe-se que muitos são os aspectos que podem ser analisados em estudos sobre o estado da arte, incluindo indicadores bibliométricos. Porém, o que se torna importante ressaltar é que estudos dessa natureza devem ser sempre considerados inconclusos, isso no sentido de que o estado do conhecimento não pode ser finito. Na medida em que a produção científica de determinada área se renova, em movimentos ininterruptos, novas pesquisas sobre o estado da arte são necessárias e importantes (TEIXEIRA, 2006).

Destaca-se que, para esta pesquisa sobre a produção científica em ações coletivas no agronegócio (a partir de teses e dissertações), são analisados diversos aspectos, entre eles: a quantificação dos programas de pós-graduação stricto sensu e da produção científica; a localização geográfica dos programas, da produção científica e dos modelos empíricos estudados; a divisão da produção científica por ano, por área e por enfoque teórico; a indicação dos orientadores na temática, bem como de possíveis linhas de pesquisa já consolidadas e autores mais citados; a indicação dos segmentos mais investigados pelos estudos e a opção metodológica das teses e dissertações. Portanto, assim como sugerido por Ferreira (2002), este estudo também responde a aspectos relacionados a "quando", "onde", "o que" e "como".

\section{Procedimentos metodológicos}

Este estudo caracteriza-se como quantitativo e qualitativo a partir de uma análise do estado da arte na área de ações coletivas no agronegócio e de uma pesquisa bibliométrica. Em relação aos estudos sobre o estado da arte, Antonello (2002), Ferreira (2002) e Teixeira (2006) afirmam que esses são necessários para o desenvolvimento de um determinado campo, uma vez que compreendem o conhecimento de uma determinada temática, em um período específico, a partir do mapeamento, da sistematização e da análise da produção científica. Já no que se refere à pesquisa bibliométrica, Araújo (2006) cita que a mesma permite a medição dos índices de produção e disseminação do conhecimento científico, revelando o comportamento da literatura em uma determinada área. Também Pritchard (1969) já definia que estudos bibliométricos são aqueles que quantificam a comunicação escrita num campo de conhecimento específico, isso para o registro sobre a evolução da produção científica e as suas características.

No que tange à população de pesquisa, esta é composta pelos 205 programas de pós-graduação stricto sensu de nível acadêmico (excluindo, assim, os de nível profissional), nas subáreas de: Administração (Administração, Ciências Contábeis e Turismo), Economia e Planejamento Urbano e Regional (Planejamento Urbano e Regional e Demografia). Essa delimitação se justifica por dois principais motivos: primeiramente, por essas subáreas pertencerem à grande área de Ciências Sociais Aplicadas, na qual o programa de pós-graduação em Desenvolvimento Regional e Agronegócio (programa que originou esta pesquisa) está inserido; posteriormente, porque a partir da grande área de Ciências Sociais Aplicadas analisaram-se as subáreas consideradas mais relacionadas com a linha de pesquisa de ações coletivas e agronegócio.

A coleta de dados ocorreu a partir dos seguintes passos. Primeiro, foram selecionados todos os programas de mestrado e doutorado em Administração (da área de Administração, 
Ciências Contábeis e Turismo), Economia e Planejamento Urbano e Regional (da área de Planejamento Urbano e Regional e Demografia), a partir do banco de dados da Coordenação de Aperfeiçoamento de Pessoal de Nível Superior (Capes), o qual dispõe de uma lista com todos os programas de pós-graduação stricto sensu recomendados e reconhecidos pela instituição.

Num segundo momento, buscou-se a lista de teses e dissertações defendidas por todos esses programas de pós-graduação (mestrado acadêmico e doutorado) nas três subáreas. Essa lista é disponibilizada também pela Capes, junto às informações dos cursos recomendados e reconhecidos pela instituição, em um campo denominado "Caderno de Indicadores". A delimitação por teses e dissertações se deu em função de que essas retratam, na maioria das vezes, linhas de pesquisa presentes nos cursos de mestrado e doutorado. Além disso, entende-se que outras publicações, como artigos científicos, capítulos e livros, muitas vezes refletem os resultados das teses e dissertações e, por isso, não foram objeto de análise deste estudo.

Com a posse dos Cadernos de Indicadores de todos os programas (das três subáreas selecionadas), o terceiro passo foi a leitura de todos os títulos e, quando disponível, das palavras-chaves de todas as 23.134 teses e dissertações defendidas entre 1998 e 2012. A opção por iniciar a seleção dos trabalhos pela leitura dos títulos deveu-se ao fato de que os títulos normalmente anunciam as informações principais das teses e dissertações, indicando os elementos que caracterizam o conteúdo inserido em seu interior (FERREIRA, 2002).

Durante o processo de leitura e seleção, primeiramente, não se focou na busca por trabalhos que abordassem exclusivamente ações coletivas no agronegócio, mas sim que indicassem estudos em um campo mais amplo, o das ações coletivas. Essa busca ocorreu a partir das seguintes palavras ou frases que indicassem ações coletivas: cooperativas, cooperativismo, cooperação, coopetição, decisões conjuntas, planejamento conjunto, cluster, arranjo produtivo local, associações, associativismo, fusões, parcerias, sistemas complexos, polo, redes, redes de cooperação, redes organizacionais, alianças, sindicatos, conflitos, cooperação, coordenação interorganizacional, interdependência organizacional, governança horizontal, relações interorga-nizacionais, circuitos, benefícios compartilhados, terceiro setor, resultados coletivos, coletividade, ações coletivas, entre outros. Salienta-se aqui que tais termos são encontrados no arcabouço teórico de ações coletivas, por diferentes autores, tais como: Granovetter (1973), Ostrom (1990), Olson (1999), Ménard (2004), Ostrom (2007) e Zylbersztajn (2010). Depois da leitura de todos os títulos das 23.134 teses e dissertações, foi possível selecionar 1.779 trabalhos sobre ações coletivas.

O passo seguinte foi a seleção das teses e dissertações no campo de ações coletivas no agronegócio. Para tanto, foram lidos novamente os títulos e as palavras-chave dos 1.779 trabalhos previamente selecionados sobre ações coletivas e, a partir deles, criou-se um banco de dados com as teses e dissertações que se tornariam foco de análise. Nessa busca, optou-se por empregar como parâmetros palavras que indicassem agronegócio, tais como: agribusiness, agricultura, cadeias produtivas, cadeias agroalimentares, pecuária ou agropecuária, agroindústria ou agroindustrial e os mais diversos segmentos ou SAGs que indicassem ramos do agronegócio. Assim, com base nessa busca, foram encontradas 282 pesquisas na temática de ações coletivas no agronegócio.

Com os dados das 282 teses e dissertações dedicadas ao estudo das ações coletivas no agronegócio, iniciou-se o processo de busca pelos arquivos completos dos trabalhos no meio eletrônico. Ao final da busca, foi possível localizar 207 estudos, os quais se tornaram o foco desta pesquisa. As outras 75 teses e dissertações não encontradas eletronicamente se referem, em sua maioria, correspondendo a $64 \%$, a trabalhos defendidos nos primeiros anos do período em análise (1998 a 2004), quando muitos programas e instituições ainda não possuíam acervo eletrônico. Todos esses 207 estudos foram então classificados por subáreas de conhecimento (Administração, Economia e Planejamento Urbano e Regional) e por ano de 
defesa, revelando os programas que mais se destacaram na quantidade de estudos encontrados no campo das ações coletivas no agribusiness. A partir desses procedimentos, foi possível cumprir o primeiro objetivo desta pesquisa, de forma a responder questões relacionadas ao assunto em estudo, ou seja, "o que" foi produzido na área de ações coletivas no agronegócio, e ao momento, isto é, "quando" essa produção científica ocorreu.

Já os dois outros objetivos específicos deste estudo foram cumpridos por meio de dados coletados no corpo do texto das 207 teses e dissertações selecionadas. Esses dados contemplam: os enfoques teóricos mais utilizados para embasar os estudos, os modelos aplicados mais estudados, os procedimentos metodológicos adotados, a localização geográfica dos estudos e a localização geográfica dos modelos coletivos investigados nos estudos empíricos. Logo, o segundo objetivo específico buscou responder a aspectos sobre o modo, isto é, "como" os estudos científicos na área de ações coletivas no agronegócio foram desenvolvidos. Por conseguinte, o último objetivo específico atendeu à questão relacionada ao local, ou seja, "onde" os estudos científicos e os modelos aplicados de ações coletivas estão ocorrendo.

No que se refere à análise dos dados, foi trabalhado com o auxílio dos softwares Excel, por meio de tabelas e gráficos que facilitam a visualização dos dados coletados, e TerraView, ferramenta des- tinada à criação de mapas temáticos, que possibilitou a demonstração da concentração geográfica dos cursos, das teses e dissertações e dos modelos coletivos aplicados estudados empiricamente nessas teses e dissertações. A partir disso, a interpretação dos dados foi feita com base em análise descritiva.

\section{Resultados e discussão}

Esta parte do estudo foi subdividida de acordo com os objetivos específicos, traçados a partir das seguintes categorias de análise: descrição dos estudos na temática de ações coletivas no agronegócio; investigação dos aspectos teórico-empírico-metodológicos, que fundamentam essas teses e dissertações; e demonstração da concentração geográfica das teses e dissertações encontradas na temática e dos objetos de investigação desses estudos.

\subsection{Caracterização dos estudos-foco de investigação}

Em relação à informação sobre a quantidade de trabalhos defendidos por ano (1998 a 2012) e o número de teses e dissertações sobre ações coletivas, também por ano, essas podem ser visualizadas na Figura 1.

Figura 1. Total de trabalhos defendidos e total de teses e dissertações em ações coletivas (por ano)

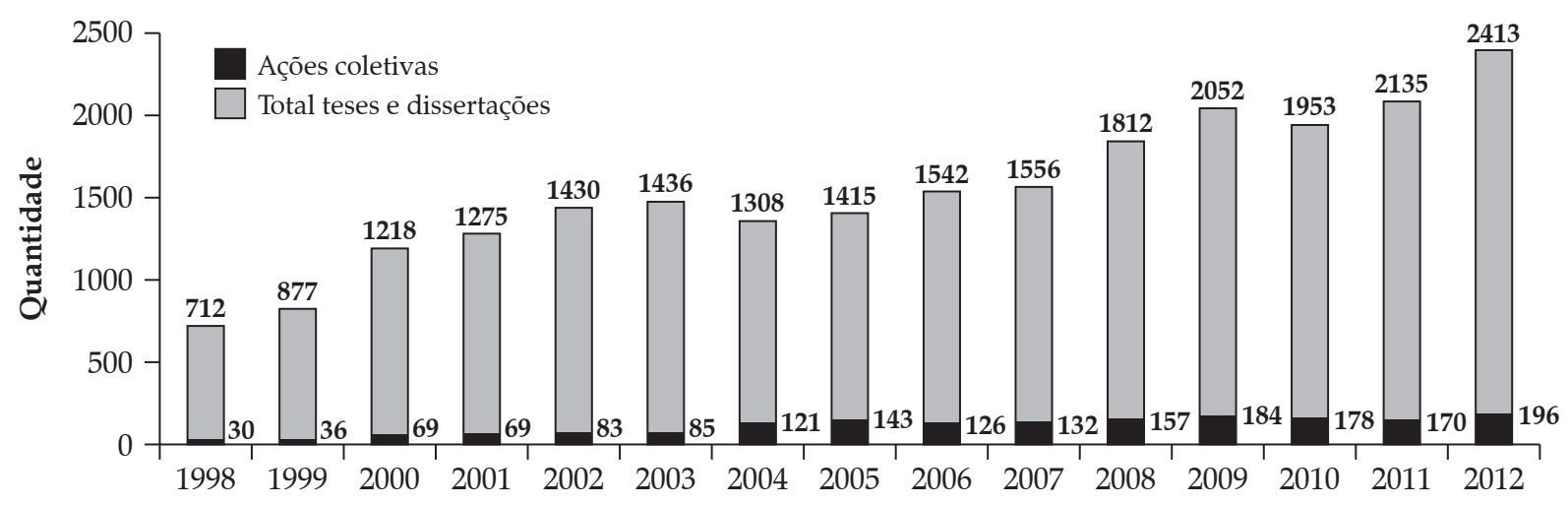

Fonte: Resultado da pesquisa. 
De modo geral, observa-se (na Figura 1) uma tendência de crescimento no número de teses e dissertações defendidas no decorrer dos anos nas três áreas de conhecimento, conjuntamente. Isso pode ser explicado, pelo menos em parte, pela promoção de políticas públicas voltadas à intensificação de programas e de cursos de pós-graduação nas mais diversas áreas, e não apenas nas que são foco deste estudo. Conforme Santos e Azevedo (2009) e Capes (2014), nos anos 1960 havia somente 38 cursos de pós-graduação (11 de doutorado e 27 de mestrado) reconhecidos pelas Capes. Já em 2008, esse número era de 2.588 e, na última avaliação trienal (2010-2012), foram analisados 5.082 cursos (1.792 de doutorado, 2.893 de mestrado e 397 de mestrado profissional), resultantes de 3.337 programas de pós-graduação. Já, em 2014, o total de cursos reconhecidos pela Capes foi de 5.689, sendo 1.945 de doutorado, 3.165 de mestrado e 579 de mestrado profissional.

Ainda sobre a Figura 1, agora em relação aos trabalhos encontrados na temática de ações coletivas, também se percebe que o número de teses e dissertações aumentou no decorrer do tempo: no início do período, em 1998, foram encontrados apenas 30, sendo que, em 2012, foram defendidos 196 estudos nessa área, totalizando 1.779 teses e dissertações sobre ações coletivas no período analisado. Acredita-se que esse aumento seja em função das décadas de 1990 e de 2000 terem marcado maior frequência de discussões sobre ações coletivas, de estudos empíricos e de publicações sobre a temática (MÉNARD, 2004; MÉNARD e KLEIN, 2004), em áreas como a de Economia, a exemplo das reflexões que passaram a integrar a Economia dos Custos de Transação (ECT), a partir de estudos como o de Williamson (1991), sobre estruturas híbridas/complexas/intermediárias e governança.

O próximo passo neste estudo foi analisar os trabalhos que abordavam especificamente ações coletivas no contexto do agronegócio, que totalizam 207 trabalhos. Esses estudos foram divididos por área de conhecimento, sendo que 143 $(69,1 \%)$ são da área de Administração, 46 (22,2\%) da de Economia e 18 (8,7\%) da de Planejamento Urbano e Regional. Isso pode estar relacionado com o maior número de cursos e, também, com a maior quantidade de teses e dissertações defendidas nos cursos de Administração em comparação com as duas outras áreas. Enquanto a área de Administração possui 100 cursos e 13.848 trabalhos defendidos no período, os cursos de Economia e Planejamento Urbano e Regional somam 69 e 36 cursos, respectivamente. Já em termos de defesas, a área de Economia teve 7.171 teses e dissertações defendidas, enquanto que a de Planejamento Urbano e Regional teve apenas 2.115. Além disso, outro fator a comentar é que a área de Planejamento Urbano e Regional é bem mais recente do que as outras duas, cujos programas e defesas passaram a aumentar somente a partir da segunda metade da década de 2000. Cabe dizer, ainda, que, apesar das áreas de Economia e Planejamento Urbano e Regional oferecerem diversas linhas de pesquisa relacionadas ao desenvolvimento econômico e local, ramo em que as ações coletivas são de fundamental importância, o estudo das mesmas ainda é menos recorrente do que na área de Administração.

$\mathrm{Na}$ sequência, observou-se o panorama das defesas dos trabalhos de ações coletivas no contexto do agronegócio no decorrer dos anos (Figura 2).

Com base na Figura 2, é possível visualizar que a quantidade de teses e dissertações na temática de ações coletivas no agronegócio tem aumentado com o passar dos anos, ainda que de forma tímida. A partir de 2005, principalmente, é que se observa de maneira mais clara o crescimento no número de trabalhos defendidos na área, com destaque para 2009, quando quase 40 estudos sobre ações coletivas no agronegócio foram defendidos.

O próximo aspecto observado se refere aos programas stricto sensu que mais se destacaram em relação a teses (TE) e dissertações (DI) defendidas no campo das ações coletivas no agronegócio. Na área de Administração, esses programas estão relacionados na Tabela 1. 
Figura 2. Teses e dissertações sobre ações coletivas no agronegócio defendidas ao longo do período

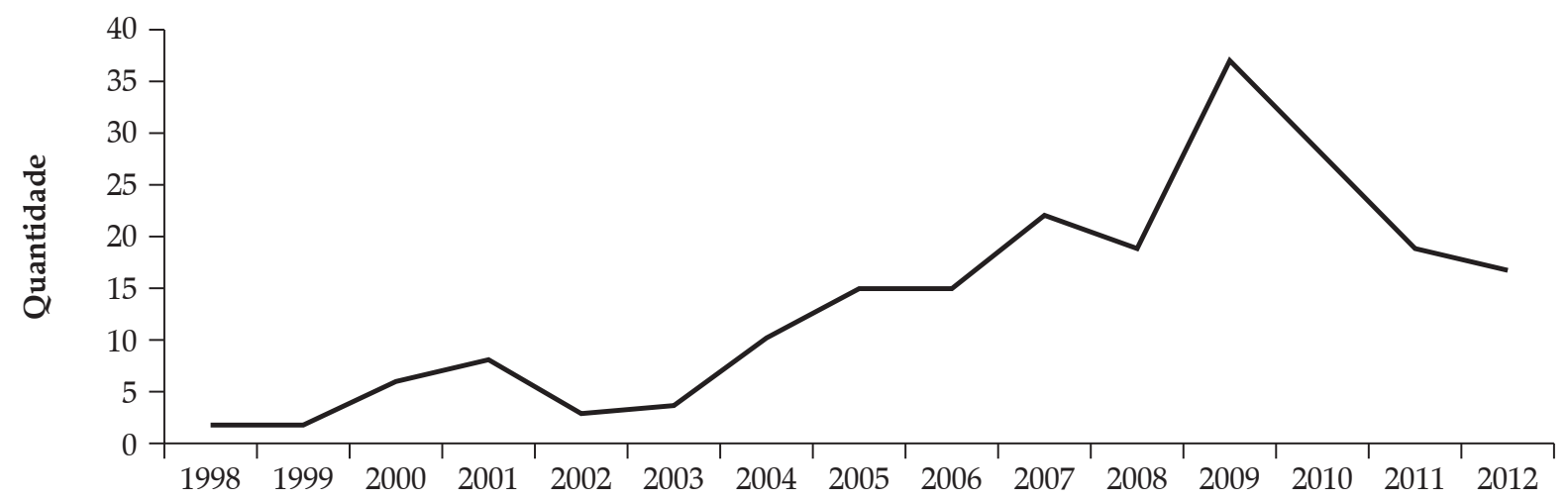

Fonte: Resultado da pesquisa.

Tabela 1. Os cinco programas de Administração com mais trabalhos em ações coletivas no agronegócio

\begin{tabular}{llccc}
\hline \multicolumn{1}{c}{ Programa } & Instituição & TE & DI & Total \\
\hline M/D Administração & Universidade Federal do Paraná/PR (UFPR) & 1 & 18 & 19 \\
M/D Administração & Universidade Federal de Lavras/MG (Ufla) & 4 & 11 & 15 \\
M/D Administração & Universidade Federal do Rio Grande do Sul/RS (UFRGS) & 6 & 8 & 14 \\
M/D Administração & Universidade de São Paulo/SP (USP) & 10 & 3 & 13 \\
M/D Administração & Universidade do Vale do Rio dos Sinos/RS (Unisinos) & 0 & 9 & 9 \\
\hline Total & & $\mathbf{2 1}$ & $\mathbf{4 9}$ & $\mathbf{7 0}$ \\
\hline
\end{tabular}

Fonte: Resultado da pesquisa.

Pode-se visualizar, na Tabela 1, que, juntos, esses cinco programas abrangem $49 \%$ do total de trabalhos (143) defendidos sobre ações coletivas no agronegócio na área de Administração, o que pode ser considerado um percentual elevado, já que o total de programas é de 65 . Assim, o restante dos trabalhos (51\%) fica subdividido nos outros 60 programas. O que chama atenção, ainda, é o fato de que quatro programas (os primeiros da tabela) possuem 21 das 29 teses defendidas no período, ou seja, 72,4\% do total. Nesse quesito, cabe destacar o programa de pós-graduação em Administração da USP, que possui 10 das 21 teses. Esse resultado pode estar relacionado ao alto fluxo de defesas que o programa possui, pois, do total de 13.848 trabalhos apresentados na área de Administração, 1.091 foram da USP, sendo esse o programa com mais defesas da área. Já o programa com a maior quantidade de dissertações sobre ações coletivas no agronegócio foi o de
Administração da UFPR, com 18 dos 49 trabalhos. Cabe ressaltar que esses dados podem representar o resultado da consolidação de linhas de pesquisa na área de ações coletivas no agronegócio por parte desses programas e de seus pesquisadores (orientadores).

Dando continuidade à análise dos programas que mais se destacaram na quantidade de trabalhos sobre ações coletivas no agronegócio, na Tabela 2 são apresentados os de Economia. Esses cinco programas reúnem $58,7 \%$ do total de 46 teses e dissertações defendidas sobre o assunto em foco na área de Economia, percentual esse que também pode ser considerado alto, uma vez que os outros $41,3 \%$ são, então, distribuídos entre os demais 39 programas da área de Economia. Conforme a Tabela 2, o que se observa é que duas universidades do estado de São Paulo são listadas (dois programas), contemplando 10 dos 27 trabalhos defendidos na área de Economia. 
Tabela 2. Os cinco programas de Economia com mais trabalhos em ações coletivas no agronegócio

\begin{tabular}{|c|c|c|c|c|}
\hline Programa & Instituição & TE & DI & Total \\
\hline M/D Economia Aplicada & Universidade Federal de Viçosa/MG (UFV) & 2 & 4 & 6 \\
\hline M Economia Rural & Universidade Federal do Ceará/CE (UFC) & 0 & 6 & 6 \\
\hline M/D Economia Aplicada & $\begin{array}{l}\text { Universidade de São Paulo/Escola Sup. de Agricultura Luiz de Queiroz/ } \\
\text { SP (USP-Esalq) }\end{array}$ & 2 & 3 & 5 \\
\hline M/D Desenv. Econômico & Universidade Federal do Paraná/PR (UFPR) & 0 & 5 & 5 \\
\hline M/D Desenv. Econômico & Universidade Estadual de Campinas/SP (Unicamp) & 1 & 4 & 5 \\
\hline Total & & 5 & 22 & 27 \\
\hline
\end{tabular}

Fonte: Resultado da pesquisa.

Tabela 3. Programas de Planejamento Urbano e Regional com mais trabalhos em ações coletivas no agronegócio

\begin{tabular}{|c|c|c|c|c|}
\hline Programa & Instituição & TE & DI & Total \\
\hline M/D Desenv. Regional e Agronegócio & Universidade Estadual do Oeste do Paraná/PR (Unioeste) & 0 & 11 & 11 \\
\hline M/D Desenv. Regional & Universidade Regional de Blumenau/SC (FURB) & 0 & 4 & 4 \\
\hline M/D Desenv. Regional & Universidade de Santa Cruz do Sul/RS (Unisc) & 0 & 3 & 3 \\
\hline Total & & 0 & 18 & 18 \\
\hline
\end{tabular}

Fonte: Resultado da pesquisa.

A última área a ser analisada quanto aos programas que mais se destacaram é a de Planejamento Urbano e Regional (Tabela 3). Observa-se que, diferente das áreas de Administração e Economia, nesta área destacam-se apenas três programas. Isso porque somente nesses três foram encontrados estudos sobre ações coletivas no campo do agronegócio. A partir da Tabela 3, infere-se que o programa de pós-graduação em Desenvolvimento Regional e Agronegócio da Unioeste é o que mais se destaca nessa área, com 11 dos 18 trabalhos.

A última subcategoria de análise deste tópico se refere aos nomes dos professores orientadores. Especificamente no Quadro 1 são apresentados os professores que orientaram mais do que dois trabalhos na área de ações coletivas no agronegócio 4 . $\mathrm{O}$ intuito de apresentar esse dado nesta pesquisa é o de analisar a possível existência ou consolidação de linhas de pesquisa sobre ações coletivas no agronegócio nos programas de pós-graduação, visto que o fato de um mesmo professor assumir diversas orientações em uma única temática pode

4. Nos casos em que o nome do professor foi encontrado em apenas uma ou duas orientações, isso pode indicar, entre outros fatores, que foi um estudo isolado ou que o próprio mestrando ou doutorando propôs a temática. indicar a existência/solidez dessa linha de pesquisa. Isso está em conformidade com o que afirmam Souza et al. (2013, p. 564), quando apontam que as teses e dissertações representam as linhas e projetos de pesquisa dos orientadores, "que na maioria dos casos são pesquisadores seniores das suas respectivas áreas".

Das 207 teses e dissertações encontradas sobre ações coletivas no campo no agrone-gócio, apenas 93 tiveram orientadores repetidos. Isso quer dizer que 114 nomes de orientadores foram encontrados apenas uma vez, o que pode retratar a ainda incipiente consolidação de linhas de pesquisas sobre ações conjuntas no âmbito do agribusiness. Contudo, é preciso ressaltar que, em alguns programas, um mesmo professor orientou três, quatro ou até oito trabalhos na temática, o que tende a indicar um dos enfoques de pesquisa desse orientador. Além disso, outro fator que se pode observar é que o programa de Administração da USP se destacou, pois foram encontrados dois orientadores de trabalhos na temática-foco deste estudo. Esse resultado pode estar relacionado com o fato de os professores Zylbersztajn e Fava Neves serem membros ativos do Pensa, grupo que se destaca em pesquisas no campo do agronegócio. 
Quadro 1. Docentes com mais de um estudo orientado na área de ações coletivas no agronegócio

\begin{tabular}{|c|c|c|}
\hline Orientador & IES & Qtd \\
\hline \multicolumn{3}{|c|}{ Administração } \\
\hline Sergio Bulgacov & Universidade Federal do Paraná (UFPR) & 8 \\
\hline Eugênio Ávila Pedrozo & Universidade Federal do Rio Grande do Sul (UFRGS) & 4 \\
\hline Janaina Macke & Universidade de Caxias do Sul (UCS) & 4 \\
\hline Luiz Marcelo Antonialli & Universidade Federal de Lavras (Ufla) & 4 \\
\hline Roberto Max Protil & Pontifícia Universidade Católica do Paraná (PUC-PR) & 4 \\
\hline Decio Zylbersztajn & Universidade de São Paulo (USP) & 3 \\
\hline Fernando Dias Lopes & Universidade Federal do Rio Grande do Norte (UFRN) & 3 \\
\hline Marcos Fava Neves & Universidade de São Paulo (USP) & 3 \\
\hline Maria Vilma Coelho Moreira Faria & Universidade de Fortaleza (Unifor) & 3 \\
\hline \multicolumn{3}{|l|}{ ECONOMIA } \\
\hline Maria Irles de Oliveira Mayorga & Universidade Federal do Ceará (UFC) & 4 \\
\hline \multicolumn{3}{|c|}{ Planejamento Urbano e Regional } \\
\hline Valmor Schiochet & Universidade Regional de Blumenau (Furb) & 3 \\
\hline
\end{tabular}

Fonte: Resultado da pesquisa.

Findadas as análises de alguns dados gerais sobre as teses e dissertações defendidas pelas três áreas, no período 1998-2012, segue-se ao próximo objetivo específico, investigando aspectos teórico-empírico-metodológicos dos 207 estudos encontrados.

\subsection{Aspectos teórico-empírico-metodológicos dos estudos}

Inicialmente, observaram-se quais trabalhos se referem a estudos somente teóricos, quantos são somente empíricos e, consequentemente, quantos são teórico-empíricos. Do total de 207 teses e dissertações, 160 são estudos teórico-empíricos, 45 são apenas empíricos e dois são apenas teóricos. Sobre isso, é necessário considerar que as teses e dissertações classificadas como estudos "Apenas teóricos" referem-se a trabalhos que discutem algum dos enfoques teóricos da Teoria da Ação Coletiva (cooperativismo, associativismo, cluster, APL, aglomerado, empreendedorismo coletivo etc.) no campo do agronegócio, mas que não apresentam um estudo empírico (de campo) sobre alguma ação coletiva. Da mesma forma, os estudos classificados como "Apenas empíricos" tratam de teses e dissertações que não abordam em seu corpus teórico nem a Teria da Ação Coletiva e nem algum dos enfoques, mas que estudam empiricamente algum modelo coletivo. É o caso de um estudo sobre viabilidade econômica de cooperativas, por exemplo, que apresenta aspectos teóricos voltados às questões de viabilidade, porém possui como objeto de investigação uma ação coletiva do agronegócio. Por sua vez, os trabalhos "Teórico-empíricos" são os que possuem tanto um enfoque teórico sobre ações coletivas quanto um modelo aplicado relacionado com a Teoria da Ação Coletiva.

Ressaltada a questão sobre a classificação das teses e dissertações em estudos "apenas teóricos", em "apenas empíricos" ou em "teórico-empíricos", fazem-se algumas considerações sobre esses estudos. Primeiramente, sobre as pesquisas apenas teóricas, cabe dizer que ambas abordam questões relacionadas à cooperação. Um dos estudos discute as falhas de coordenação de um sistema agroindustrial complexo (da carne bovina) e comenta que a cooperação é uma das opções para diminuir tais falhas. Enquanto isso, a outra pesquisa aborda a importância de agricultores do ramo leiteiro se unirem de forma coletiva. Tratam-se de uma tese defendida na USP e uma dissertação defendida na Universidade Estadual de Maringá (UEM), respectivamente.

Já em relação às 45 teses e dissertações (22\% dos trabalhos) classificadas como estudos somente empíricos, foi possível identificar diversas teo- 
rias utilizadas (que não contemplam a Teoria da Ação Coletiva e nenhum de seus enfoques teóricos). Porém, vale destacar que, nesses estudos, as análises se referem a modelos aplicados coletivos. Os referencias teóricos que embasaram esses 45 trabalhos envolviam assuntos relacionados a: tecnologia de informação, análise econômica de projetos, matriz insumo-produto, desenvolvimento sustentável e gestão ambiental, processo de inovação, gestão estratégica, qualidade de vida, empreendedorismo, marketing, entre outros. Foram encontradas mais de 20 temáticas diferentes sobre as quais foram realizados estudos empíricos sobre cooperativas, associações, APLs, grupos informais, redes, alianças e outros modelos aplicados no formato de ações coletivas. A partir disso, pode-se dizer que ações coletivas no campo do agronegócio têm sido estudadas sob diversas perspectivas, podendo ser econômica, social, cultural ou ambiental. Isso vem ao encontro tanto dos incentivos das ações coletivas, podendo ser de cunho financeiro, social, ambiental, psicológico, cultural, político, entre outros (OLSON, 1999; BRITO, 2001), como também, da existência de pontos de vista diferentes de autores de distintas áreas. Um exemplo desse último são os casos de Olson (1999), que apresenta uma visão mais econômica das ações coletivas, e Granovetter $(1973,1985)$, que possui um enfoque mais sociológico.
No que se refere às teses e dissertações classificadas como teóricas e empíricas $(77 \%)$, vale dizer que foi encontrada uma diversidade de enfoques teóricos relacionados à Teoria da Ação Coletiva e de modelos coletivos aplicados. Esses dois aspectos (enfoque teórico e modelo aplicado) são analisados separadamente.

Sobre os enfoques teóricos, com base nos 160 trabalhos teórico-empíricos, somados aos dois estudos somente teóricos, percebeu-se que diferentes abordagens teóricas foram utilizadas para embasar as teses e dissertações (Figura 3). Sobre esse aspecto, cabe dizer que a análise da abordagem teórica utilizada pelas 162 teses ou dissertações foi feita a partir da leitura do sumário, preferencialmente dos temas abordados no capítulo destinado à fundamentação teórica. Além disso, ressalta-se que diversos estudos apresentam mais de uma abordagem, por exemplo, cooperativismo e associativismo ou redes e alianças, de maneira que foram encontrados mais de dez enfoques teóricos distintos.

A partir da Figura 3, pode-se dizer que o Cooperativismo foi a abordagem teórica mais utilizada para embasar as teses e dissertações sobre ações coletivas no agronegócio, citado por $40 \%$ dos trabalhos. Os enfoques teóricos sobre Rede e APL/Cluster/Aglomerado vêm em seguida, com $18 \%$ e $14 \%$, respectivamente. Lembra-se que, além de ser a opção deste trabalho a utiliza-

Figura 3. Enfoques teóricos abordados pelas teses e dissertações sobre ações coletivas no agronegócio

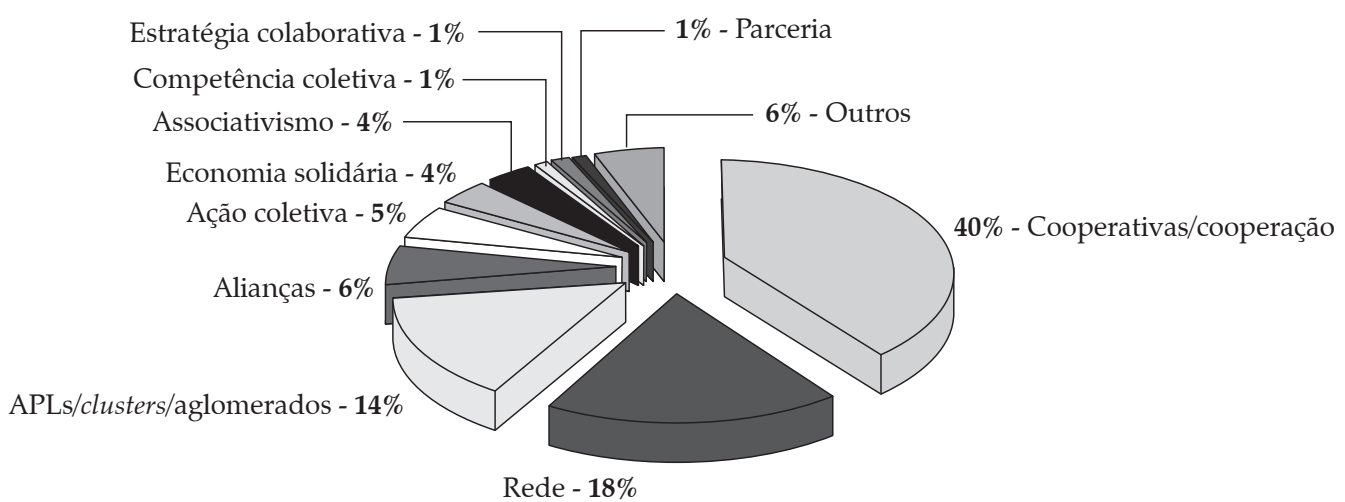

Fonte: Resultado da pesquisa. 
ção dos conceitos de APL, cluster e aglomerado como sinônimos, muitas teses e dissertações também não faziam diferenciação entre esses termos. Dessa forma, optou-se, também, por unir os termos no momento da verificação do enfoque teórico utilizado pelos trabalhos.

É importante ressaltar que as abordagens do Cooperativismo, das Redes e dos APLs/clusters/ Aglomerados foram as mais citadas nas áreas de Administração, Economia e Desenvolvimento Regional. O Cooperativismo predominou em primeiro lugar nas três áreas; as Redes, em segundo, exceto na área de Economia, em que os estudos embasados pela teoria de APLs/clusters/ Aglomerados ficaram em segundo lugar. No caso do item "Outros", esse envolve abordagens como: fusões e aquisições, empreendedorismo coletivo, participação e empoderamento, netchain, supply chain management, entre outras que foram utilizadas por apenas uma tese ou dissertação e que juntas somam $6 \%$ dos trabalhos.

Outro dado que chama atenção na Figura 3 é que apenas 5\% dos estudos apresentam a Teoria da Ação Coletiva como embasamento para a pesquisa. Ou seja, por mais que a maioria (162 estudos) apresente alguma abordagem relacionada à coletividade, poucos trazem a teoria como tema central; poucos se debruçam de forma aprofundada sobre a essência da Teoria da Ação Coletiva. Mesmo assim, não se pode afirmar que isso indica uma fragilidade nas pesquisas, mas sim que os mais diversos enfoques teóricos ligados às ações coletivas respondem, por si só, de forma satisfatória e coerente aos achados empíricos descritos pelos pesquisadores. É o caso, por exemplo, das abordagens do Cooperativismo, de Redes, de APLs/Clusters/Aglomerados e de Economia Solidária, que possuem ferramentais teóricos já estudados e desenvolvidos desde longa data por autores de renome e com pesquisas sólidas (como será visto logo adiante). Assim, dependendo do caso analisado, dispensam a utilização de uma teoria central (como a Teoria da Ação Coletiva) para embasar a pesquisa. No entanto, acredita-se que a utilização da Teoria da Ação Coletiva pode enriquecer ainda mais os constructos teóricos e empíricos, bem como despertar o interesse de pesquisadores por novas e diferentes análises, em função das diversas variáveis estudadas e instigadas pela teoria, tais como: racionalidade coletiva, tamanho do grupo, heterogeneidade, falhas coletivas, divisão dos benefícios, comunicação face a face, entre outros citados por Granovetter (1973, 1985), Olson (1999) e Ostrom (1990, 2007).

Depois dos enfoques teóricos, buscou-se saber quais foram os modelos aplicados estudados nos casos das teses e dissertações empíricas (Figura 4). São, no total, 205 teses e dissertações (já que apenas duas são somente teóricas) que retratam estudos empíricos e, assim, abordam estudos sobre algum modelo coletivo aplicado. Dentre esses trabalhos, muitas teses e dissertações apontam e estudam mais do que um modelo aplicado de ação coletiva, por exemplo, uma cooperativa e uma associação, de modo que foram encontradas mais de 11 diferentes formas organizacionais.

Com base na Figura 4, percebe-se que as cooperativas foram objeto de investigação de $48 \%$ das teses e dissertações, o equivalente a 108 trabalhos. Sendo assim, da mesma forma que o enfoque teórico (Figura 3), em que o Cooperativismo foi o mais utilizado, as cooperativas ficaram em primeiro lugar como objeto de estudo nas áreas de Administração, Economia e Planejamento Urbano e Regional. Isso pode ser explicado pelo fato de o Brasil ser considerado um país cooperativista, em que as cooperativas estão muito presentes nos mais diversos setores, especialmente no agronegócio, sendo responsável por mais de 5\% do PIB nacional (BIALOSKORSKI NETO, 2004; OCB, 2014). Segundo a OCB (2015), atualmente, o cooperativismo brasileiro está estruturado e é fundamental para a economia do País, possuindo o objetivo de ser cada vez mais conhecido e entendido como um sistema integrado e forte. Acredita-se que, por questões como essas, estudos empíricos sobre esses modelos coletivos sejam com tamanha frequência realizados. 
Figura 4. Modelos aplicados de ações coletivas abordados nas teses e dissertações

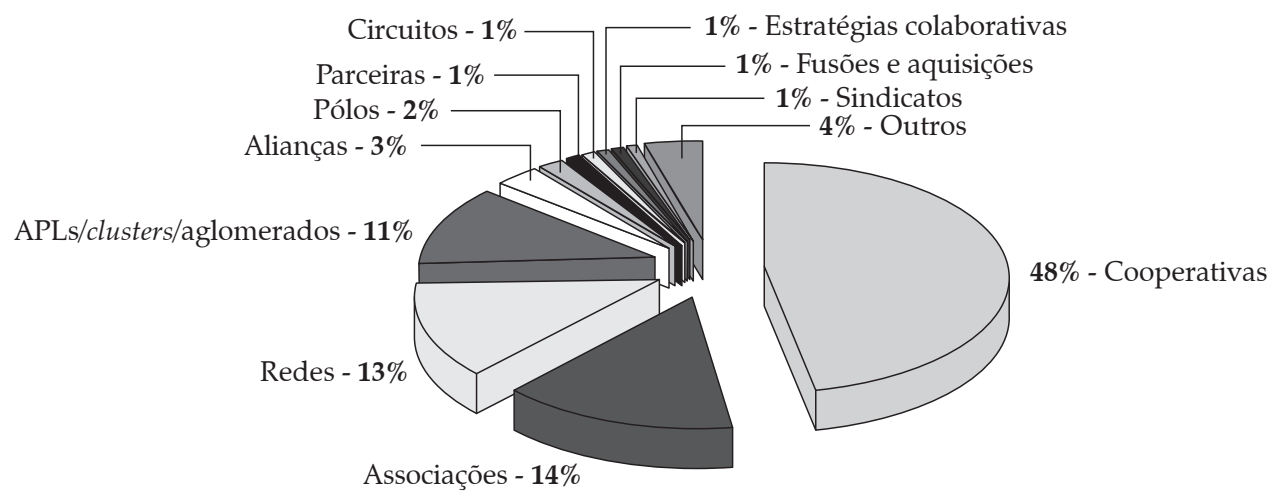

Fonte: Resultado da pesquisa.

Depois das cooperativas, as associações foram as estruturas coletivas mais estudadas. De acordo com a Figura 4, $14 \%$ das teses e dissertações realizaram estudos de caso em associações, índice seguido de perto pelos trabalhos realizados sobre redes $(13 \%)$. Percebe-se que, diferentemente da ordem dos enfoques teóricos, em que o associativismo está em sétimo lugar (Figura 3), as associações assumem o segundo lugar quando se refere aos modelos coletivos estudados empiricamente. Nesse aspecto, cabe lembrar que algumas abordagens teóricas podem ser utilizadas para embasar estudos de diferentes modelos aplicados, como é o caso do enfoque teórico de Redes, por exemplo. Observou-se que, muitas vezes, a teoria das teses e dissertações versava sobre Redes, mas o caso empírico era sobre uma associação, isso porque, no decorrer da fundamentação teórica, os pesquisadores indicavam que Redes podem ser diversas formas de associativismo, cooperativismo, alianças, entre outros. Assim, deve-se lembrar que os diferentes enfoques teóricos e modelos aplicados aqui relacionados fazem parte de uma teoria central, a Teoria da Ação Coletiva, e que podem, dessa forma, estar interligados e correlacionados, dependendo da maneira como cada pesquisador os apresenta e os estuda.

Posterior às cooperativas, associações e redes, os APLs/clusters/aglomerados foram foco de estudo de $11 \%$ das teses e dissertações, sendo que as demais formas coletivas estudadas foram: alianças, polos, parcerias, circuitos, estratégias colaborativas, fusões e aquisições e sindicatos. Além desses, no critério "Outros", ainda foram encontrados: projetos, programas, empreendimentos coletivos, coletivos de produção, relações interorganizacionais, organizações associativas e cooperação interinstitucional.

O último aspecto teórico-empírico analisado se refere aos SAGs ou segmentos mais estudados nas teses e dissertações de ações coletivas no agronegócio nas três diferentes subáreas. Na Tabela 4, apresentam-se os segmentos que mais foram estudados. Esclarece-se que algumas teses e dissertações realizaram estudos em mais de um segmento, o que justifica a quantidade de 226 segmentos. Ainda, ressalta-se que, por mais que segmentos como o leite, a bovinocultura, a avicultura etc., possam ser incluídas no item "agropecuária", decidiu-se por não unificá-los, mantendo os SAGs ou segmentos, tal como foram citados nas teses e dissertações. Isso porque a união de SAGs, como, por exemplo, o do leite, o da suinocultura, o da bovinocultura ou, ainda, de grãos (café, trigo e soja) em um único item deixaria de demonstrar a representatividade que cada um está tendo nos estudos sobre ações coletivas no agronegócio. 
Tabela 4. SAGs ou segmentos mais estudados

\begin{tabular}{lcc}
\hline \multicolumn{1}{c}{ SAG/Segmento } & Quantidade & Participação \\
\hline Agropecuária & 37 & $16,4 \%$ \\
Leite & 20 & $8,8 \%$ \\
Hortifruticultura & 19 & $8,4 \%$ \\
Agroindustrial & 17 & $7,5 \%$ \\
Café & 17 & $7,5 \%$ \\
Vitivinícola & 17 & $7,5 \%$ \\
Agricultura familiar & 15 & $6,6 \%$ \\
Agricultura orgânica/agroecologia & 10 & $4,4 \%$ \\
Suinocultura & 9 & $4,0 \%$ \\
Crédito rural & 8 & $3,5 \%$ \\
Piscicultura & 8 & $3,5 \%$ \\
Trigo & 7 & $3,1 \%$ \\
Bovinocultura & 6 & $2,7 \%$ \\
Avicultura & 5 & $2,2 \%$ \\
Soja & 5 & $2,2 \%$ \\
Outros & 26 & $11,5 \%$ \\
\hline Total & $\mathbf{2 2 6}$ & $\mathbf{1 0 0 \%}$ \\
\hline Fonte: Resultado da pesquisa. & &
\end{tabular}

A partir do detalhamento dos setores mais estudados, de acordo com a Tabela 4, observa-se que o ramo agropecuário é o mais estudado (em $16,4 \%$ dos trabalhos). Um dos motivos para isso pode ser a notoriedade da pecuária no Brasil, uma vez que, segundo o Centro de Estudos Avançados em Economia Aplicada - Cepea (2015a), sua participação no PIB nacional foi de 6,8\% em 2013 (último dado disponível). Além disso, como já exposto anteriormente, o Cooperativismo foi o enfoque teórico e o modelo aplicado mais utilizado nos estudos empíricos, fator esse que ajuda a justificar o fato de a agropecuária ser tão estudada, já que diversas pesquisas foram realizadas tendo como objeto-alvo de estudo as cooperativas agropecuárias. Da mesma forma, o ramo agroindustrial, estudado por 7,5\% das teses e dissertações, também segue a mesma justificativa: muitos estudos eram sobre cooperativas agroindustriais.

Outro aspecto que chamou a atenção é o fato de que o setor leiteiro e a hortifruticultura foram os próximos segmentos mais citados. O que pode explicar isso é o aumento da produção nacional de leite, que, segundo Maia et al. (2013), vem crescendo a taxas relativamente constantes desde 1974. Em relação à hortifruticultura, a busca por alimentos saudáveis, a melhor distribuição de renda e os novos polos, que vêm se destacando na cultura de hortaliças e frutas, podem ser justificativas para o número de estudos no setor. Esses novos polos, conforme Cepea (2015b), são: o Rio Grande do Norte, o Ceará e locais como o Vale do São Francisco, Irecê e Chapada Diamantina, na Bahia; Cristalina, em Goiás; o norte de Minas e o Triângulo Mineiro/Alto Paranaíba.

Após as análises sobre os aspectos teórico-empíricos, desenvolveram-se análises sobre questões metodológicas, especificamente sobre o tipo da abordagem metodológica (qualitativa ou quantitativa) (Tabela 5).

Conforme pode ser observado na Tabela 5, os estudos qualitativos (97) predominaram entre teses e dissertações, totalizando $46,9 \%$. Um dos fatores que pode indicar o porquê desse índice é o fato de que as pesquisas, em sua maioria, referem-se a estudos de caso. Isso pode ser considerado positivo, uma vez que esses estudos de caso levam em consideração a existência de muitos participantes atuando de forma simultânea, cenário recorrente nos sistemas agroindustriais. Mas, por outro lado, pode ser negativo, pois se referem a estudos de natureza descritiva, baseados em casos específicos, não podendo ser generalizados (ZYLBERSZTAJN, 2010). 
Tabela 5. Abordagem metodológica utilizada pelos estudos sobre ações coletivas no agronegócio

\begin{tabular}{lccccc}
\hline \multicolumn{1}{c}{ Abordagem } & Administração & Economia & $\begin{array}{c}\text { Planejamento Urbano } \\
\text { e Regional }\end{array}$ & Total & $\%$ \\
\hline Qualitativa & 83 & 8 & 6 & 97 & $46,9 \%$ \\
Qualitativa/quantitativa & 33 & 7 & 6 & 46 & $22,2 \%$ \\
Quantitativa & 12 & 1 & 2 & 15 & $7,2 \%$ \\
Não informado & 15 & 30 & 4 & 49 & $23,7 \%$ \\
\hline Total & $\mathbf{1 4 3}$ & $\mathbf{4 6}$ & $\mathbf{1 8}$ & $\mathbf{2 0 7}$ & $\mathbf{1 0 0 \%}$ \\
\hline
\end{tabular}

Fonte: Resultado da pesquisa.

Num índice bem menor do que os trabalhos puramente qualitativos, as teses e disserta-ções com abordagem unicamente quantitativa representaram $7,2 \%$. Cabe dizer que os estudos de cunho qualitativo não devem ser considerados mais ou menos confiáveis do que os de cunho quantitativo; aliás, não existe uma abordagem mais ou menos científica, elas possuem características diferentes e, muitas vezes, complementares, fazendo com que, do ponto de vista epistemológico, ambas façam parte de um mesmo método científico (MINAYO e SANCHES, 1993). Já os trabalhos que combinaram pesquisa qualitativa e quantitativa somaram $22,2 \%$, o que, para Serapioni (2000), é um fator muito positivo, pois a combinação entre os dois métodos se revela uma forma estratégica e evidencia riqueza em termos de análise de problemas e situações.

No que se refere aos trabalhos que não informaram o tipo da abordagem metodológica, esses somaram $23,7 \%$, um percentual que pode ser considerado elevado. Sobre esse aspecto, Minayo (2010) afirma que a especificação da abordagem metodológica num trabalho é fundamental, uma vez que faz parte da determinação e definição dos caminhos pelos quais percorreu uma determinada pesquisa até se chegar aos resultados. Além disso, pontuar o método de pesquisa é necessário como parâmetro para o pesquisador caminhar na produção do conhecimento. Dessa maneira, é fundamental para o processo evolutivo de uma área em termos científicos. Sobre isso, o que se analisou é que, do montante de 49 teses e dissertações que não informaram a abordagem metodológica, 30 trabalhos eram da área de Economia, isto é, 65,2\% do total de 46 teses e dissertações dessa área não apontaram se a pesquisa possui abordagem qualitativa e/ou quantitativa. Observando esses estudos de forma mais detalhada, percebeu-se que eles possuem uma estrutura diferente dos trabalhos das áreas de Administração e Planejamento Urbano e Regional. Em resumo, enquanto as teses e dissertações dessas duas últimas áreas geralmente apresentam um capítulo específico para os procedimentos metodológicos, com subcapítulos sobre o método, a coleta de dados e a análise de dados, as de Economia dificilmente o possuem. Em vez disso, apresentam a metodologia da pesquisa juntamente com o texto da introdução ou no capítulo dos resultados. Aspectos como esses dificultaram a coleta de dados para este estudo, de forma que mais páginas tiveram que ser lidas, em comparação aos estudos das áreas de Administração e Planejamento Urbano e Regional, até que se encontrasse de maneira confiável os reais aspectos metodológicos utilizados. Tais desafios estão de acordo com o citado por Ferreira (2002) e Teixeira (2006), sobre as dificuldades enfrentadas por pesquisadores que estudam a produção científica de determinada área.

Finalizados os aspectos teórico-empírico-metodológicos, no próximo item aborda-se o objetivo específico que discorre sobre a concentração geográfica das teses e dissertações na temática e, também, a localização dos modelos coletivos estudados nessas pesquisas.

\subsection{Concentração geográfica dos estudos e dos modelos coletivos estudados \\ O intuito dessa verificação foi o de comparar se a localização dos estudos era a mesma que a}


localização das ações coletivas estudadas, uma vez que, muitas vezes, as pesquisas investigam objetos fora do estado ou até mesmo do País. Sendo assim, na Figura 5 apresenta-se o mapa que mostra a concentração geográfica dos estudos encontrados.

Como se pode observar na Figura 5, as 207 teses e dissertações encontradas sobre o assunto em foco estão concentradas em 14 estados brasileiros, mais o Distrito Federal. Em 12 estados não foram localizados estudos no gênero, especialmente na região Norte. De modo geral, a maior quantidade de estudos sobre ações coletivas no agronegócio está localizada no Sul e no Sudeste. Os dois estados nos quais foram desenvolvidas mais pesquisas sobre ações coletivas no agronegócio foram Paraná $(23,2 \%)$ e São Paulo $(20,3 \%)$ que, conjuntamente, possuem $43,5 \%$ do total de estudos. Se somados, ainda, com Rio Grande do Sul e Minas Gerais, os quatro estados concentram $71,6 \%$ do total de trabalhos da área.
Assim, a região Sul concentra $46,9 \%$, enquanto a Sudeste reúne $34,4 \%$, de modo que, unidas, as regiões possuem $81,3 \%$ do total de teses e dissertações.

Em termos de programas de pós-graduação stricto sensu que se destacaram nos quatro estados do Sul e do Sudeste podem ser citados:

a) Paraná: Administração e Desenvolvimento Econômico da UFPR; Desenvolvimento Regional e Agronegócio da Unioeste; Administração da PUC;

b) São Paulo: Administração, da USP; Economia Aplicada da Esalq/USP; Administração e Economia da FGV; Ciência Econômica da Unicamp;

c) Rio Grande do Sul: Administração da UFRGS; Administração da UCS; Administração da Universidade Federal de Santa Maria (UFSM);

d) Minas Gerais: Administração da UFLA; Economia da UFV.

Figura 5. Concentração geográfica das teses e dissertações em ações coletivas no agronegócio

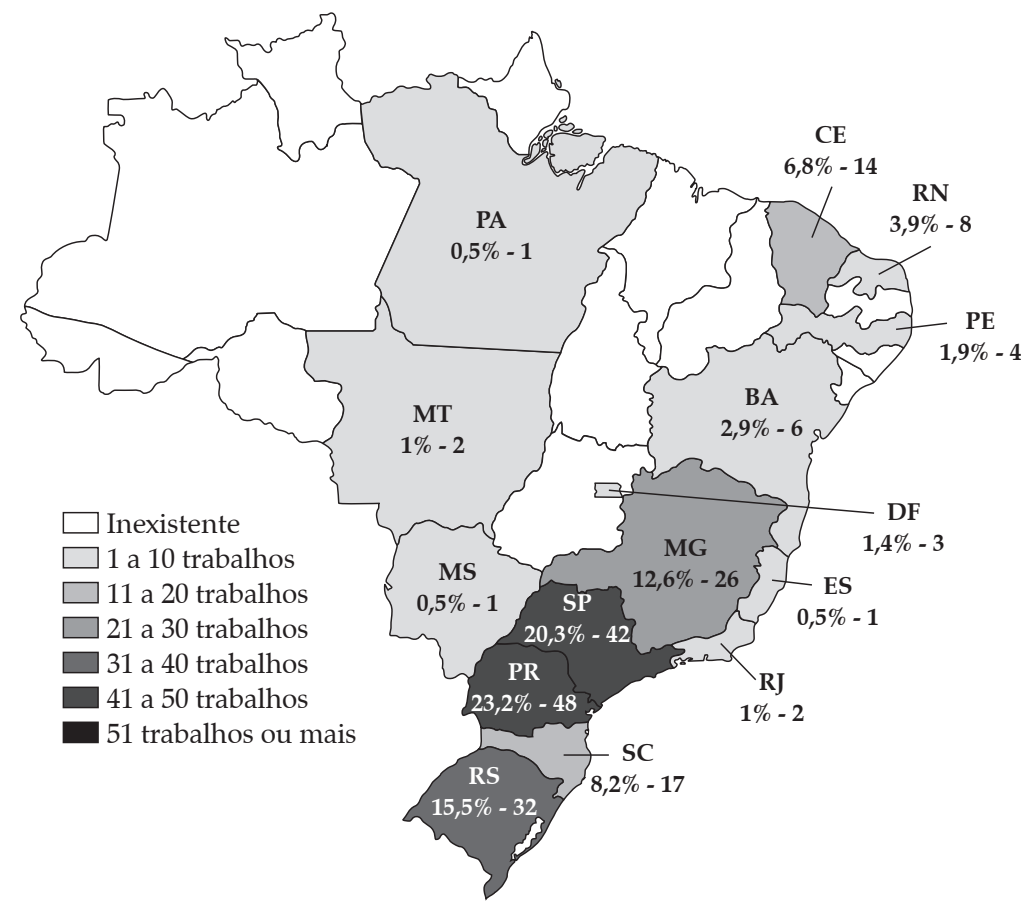

Fonte: Resultado da pesquisa. 
Figura 6. Concentração geográfica dos modelos coletivos aplicados pesquisados nos estudos empíricos

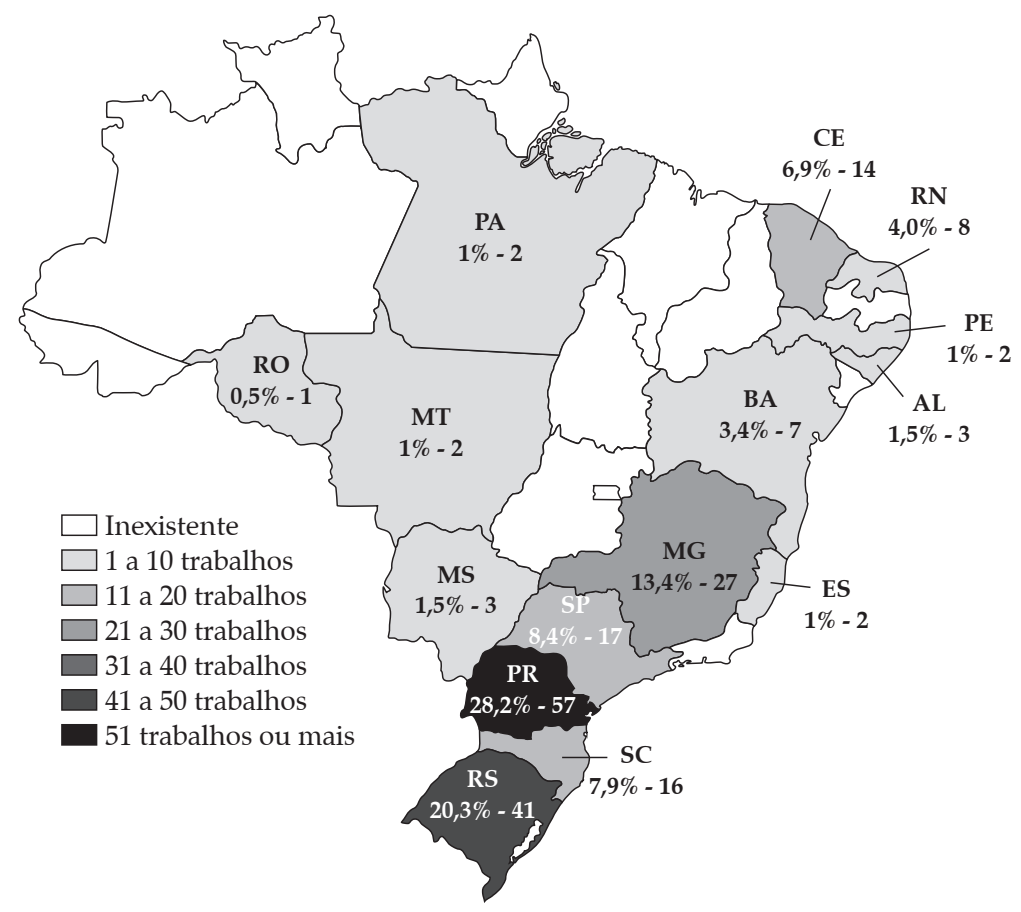

Fonte: Resultado da pesquisa.

Os estados do Nordeste em que foram encontrados estudos (Ceará, Rio Grande do Norte, Pernambuco e Bahia) concentram $15,5 \%$ dos mesmos, sendo o estado do Ceará com maior número de teses e dissertações na área (14). Nesse estado, os programas de Administração de Empresas, da Universidade de Fortaleza e Economia da Universidade Federal do Ceará, foram os programas de pós-graduação stricto sensu que mais se destacaram. Na região Norte, foi encontrado apenas um trabalho, no estado do Pará, o que pode estar relacionado com a ainda pequena quantidade de programas de mestrado e doutorado nessa região comparativamente às outras regiões do Brasil (CAPES, 2014). Por fim, na região Centro-Oeste também foram encontrados poucos trabalhos; apenas três.

Além da concentração geográfica das teses e dissertações encontradas, procurou-se saber, ainda, a localização dos modelos coletivos aplicados que foram utilizados como objeto de inves- tigação nas pesquisas empíricas (de campo), conforme demonstrado na Figura 6.

É relevante salientar que algumas teses e dissertações estudam mais de um modelo aplicado e, algumas vezes, em estados diferentes. Assim, foi assinalado um estudo para cada estado. Da mesma forma, outras pesquisas realizam observações no cenário nacional, sem a identificação de um único estado. Nesses casos, não se assinalou para nenhum estado do Brasil. Ainda, outras pesquisas foram feitas em âmbito internacional, nas quais se analisava uma determinada situação: SAG ou segmento fora do Brasil e, às vezes, comparavam as duas realidades. Entre os países estudados estão: Peru, França, Argentina, Colômbia, Nova Zelândia e Paraguai.

Ao se analisar a Figura 6, entende-se que a maior concentração de formas coletivas estudadas ocorre também nas regiões Sul e Sudeste, assim como a concentração das teses e dissertações encontradas sobre a temática (Figura 5). 
Além disso, praticamente os mesmos estados em que foram localizadas as pesquisas também são os estados nos quais os modelos aplicados estudados estão localizados. Porém, podem ser citadas algumas diferenças. A primeira delas é que dois estados onde não foram localizados estudos sobre ações coletivas no agronegócio apareceram como sendo objetos alvo de estudo: Alagoas e Rondônia, com três e um trabalhos, respectivamente. Ademais, no Distrito Federal e no Rio de Janeiro, onde foram localizadas teses e dissertações na área, não foi encontrada nenhuma aplicação empírica. Dessa forma, igualmente a Figura 5, apenas 15 estados brasileiros foram foco de estudos empíricos sobre ações coletivas no agronegócio.

Analisando os estados individualmente, um dos aspectos que se destaca é o caso de São Paulo. É possível perceber que, mesmo possuindo alta concentração de teses e dissertações no campo das ações coletivas no agronegócio (Figura 5), a concentração é bem menor quando se refere à localização dos modelos aplicados que foram estudados. Isso significa que os programas de pós-graduação de nível mestrado e doutorado têm buscado pesquisar formatos empíricos fora do estado de São Paulo. Verificando essas pesquisas, constatou-se que eram realizados estudos de caso principalmente no Paraná, no Rio Grande do Sul, em Minas Gerais e em âmbito nacional.

O estado do Paraná assume a liderança no que se refere a estudos empíricos realizados, uma vez que concentra $28,2 \%$ dos casos analisados. Aprofundando a análise desse dado, obteve-se que, na maioria dos casos, o modelo aplicado estudado foi uma cooperativa do segmento agropecuário ou agroindustrial, o que pode ser justificado pela importância do cooperativismo agropecuário/agroindustrial no Paraná. De acordo com a Organização das Cooperativas do Paraná - Ocepar (2015), existe no Paraná quase um milhão de cooperados distribuídos entre 231 cooperativas, que respondem por $13 \%$ da riqueza produzida no estado. O ramo agropecuário é o que possui o maior número de cooperativas (77), envolvendo quase 136 mil cooperados. Essas 77 cooperativas são responsáveis por 55\% da economia agrícola do Paraná e em muitos municípios é a empresa econômica mais importante, a que mais emprega e a que mais gera receitas. Assim, o cooperativismo é representativo no Paraná, especialmente a partir da participação expressiva de pequenos e médios produtores.

O estado do Rio Grande do Sul assume a segunda posição, concentrando $20,3 \%$ dos modelos coletivos aplicados pesquisados nos estudos empíricos. O cooperativismo também foi a fonte da maioria dos estudos, provavelmente por sua ampla representatividade nesse local. Segundo dados da Organização das Cooperativas do Rio Grande do Sul (OCERGS, 2015), o estado possui 464 cooperativas ativas (sendo o estado nacional com o maior número de cooperativas cadastradas - 1.041) e cerca de 2,5 milhões de cooperados, o equivalente a $21,6 \%$ do total de cooperados do Brasil (segundo maior percentual do país, ficando atrás apenas de São Paulo, que possui 3,4 milhões de associados em cooperativas). Quanto ao segmento mais estudado, a maioria das pesquisas foi realizada sobre a pecuária e sobre o ramo vitivinícola, provavelmente em função da importância desses segmentos para o estado. Existem 148 cooperativas agropecuárias no Rio Grande do Sul, sendo o maior número em comparação a outros segmentos (OCERGS, 2015). Já em relação à vitivinícola, segundo o Instituto Brasileiro do Vinho - Ibravin (2015), o estado é o maior produtor de vinhos do Brasil, responsável por $90 \%$ da produção nacional. A Serra Gaúcha é o polo mais importante do País, atendendo sozinha cerca de $85 \%$ da produção.

Em terceiro lugar encontra-se Minas Gerais, com $13,4 \%$. O segmento pecuário, especialmente o leite, foi muito estudado em Minas Gerais. Ademais, o café entrou na pauta dos grãos, foco de diversos estudos de caso. Minas Gerais é o maior produtor de leite do Brasil, com mais de nove milhões de litros em 2013 (IBGE, 2013). Além disso, é o maior produtor de café, respondendo por mais de $50 \%$ da produção nacional (ASSOCIAÇÃO BRASILEIRA DA INDÚSTRIA DO CAFÉ - ABIC, 2015), fatores esses que prova- 
velmente incitaram estudos científicos sobre isso no estado.

A partir da análise dos estados das regiões Sul e Sudeste, que mais concentraram os modelos coletivos estudados pelas teses e dissertações das áreas de Administração, Economia e Planejamento Urbano e Regional, é possível dizer que, conjuntamente, essas duas regiões possuem $79,2 \%$ das formas coletivas estudadas empiricamente. Porém, a região Sul, individualmente, responde por $56,4 \%$, ou seja, mais da metade das teses e dissertações encontradas na temática de ações coletivas no agronegócio estudou modelos coletivos localizados no Sul do País. Esse resultado pode estar associado à recorrência de estudos com foco em cooperativas agropecuárias/ agroindustriais, tão presentes em toda a região Sul do Brasil. Essa região é reconhecida pelos aspectos coletivistas, principalmente em função das características culturais cooperativistas da população, já que esta é formada, em grande maioria, por imigrantes europeus e esses representam o berço do cooperativismo (SILVA NETO et al., 2000).

\section{Conclusões e considerações finais}

$\mathrm{O}$ objetivo que motivou esta pesquisa foi o de compreender a produção científica no Brasil sobre ações coletivas no agronegócio. Sendo assim, após o término do estudo, algumas considerações podem ser tecidas. Uma delas é em relação às contribuições do estudo. De acordo com o que afirmam autores como Macias-Chapula (1998), Ferreira (2002), Antonello (2002), Teixeira (2006) e Momm (2009), pesquisas sobre o estado da arte colaboram significativamente para a geração de conhecimento em determinada área; neste caso, mais especificamente para a temática de ações coletivas no agronegócio.

A partir da análise dos resultados desta pesquisa, de maneira geral, pode-se dizer que o cenário da produção científica nacional sobre ações coletivas no agronegócio é positivo. Isso no sentido de que foram encontrados estu- dos científicos, com rigor e comprovação metodológica, e constatou-se que esses estudos têm aumentado, mesmo que em pequenas quantidades. Tal constatação está em concordância com o que autores citam sobre o aumento no número de estudos sobre formas coletivas nas últimas décadas. Entretanto, entende-se que o total de teses e dissertações encontradas ainda representa um número relativamente baixo se considerado o que defendem diversos autores (tais como MÉNARD, 2004; ZYLBERSZTAJN, 2005b) de que as ações coletivas são estruturas de governança cada vez mais recorrentes no agronegócio. Assim, concorda-se com o que dizem Austin (2001), Ménard (2004) e Zylbersztajn (2005b), que o esforço voltado ao entendimento e à aplicação de ações coletivas ainda é considerado pequeno e incipiente, de forma que essa área de estudo precisa ser mais explorada.

Vale considerar, também, que esse cenário poderia se apresentar de forma diferente tendo como objeto de análise artigos científicos, como é o apontado pelo estudo de Schmidt et al. (2014). Contudo, é importante ressaltar que a escolha por analisar teses e dissertações deveu-se ao fato de elas representarem, na maioria das vezes, as linhas de pesquisa presentes nos cursos de mestrado e doutorado, isto é, dificilmente orientadores assumem pesquisas em áreas totalmente distintas das que estudam. Assim, a partir da localização de teses e dissertações no campo das ações coletivas no agronegócio, sabe-se que existem linhas de pesquisa na área e que, portanto, tais estudos tendem a ter seguimento.

Ponderando sobre essas questões, algumas sugestões são tecidas para os pesquisadores da área. O primeiro aspecto que se ressalta é o profícuo campo de pesquisa que se tem a partir de ações coletivas no agronegócio. Como foi concluído, as ações coletivas são de fato notáveis no agronegócio e assumem diversos formatos, nos mais diferentes segmentos. Estudá-las é uma forma de auxiliar no apontamento de melhores formas de geri-las ou, ainda, de fomentar políticas públicas que ajudam no desenvolvimento das mesmas. Depois disso, chama-se a atenção 
dos pesquisadores para a realização de pesquisas em SAGs ou segmentos diferentes dos que, muitas vezes, são os maiores e mais representativos de um determinado estado ou do país. Estudos científicos a partir de ramos iniciantes e que acabam de surgir na pauta de produtos ou serviços importantes para a economia nacional tendem a ser valorizados no campo acadêmico ou, até mesmo, na esfera público-privada, podendo auxiliar no apontamento de direções a serem tomadas para melhorar tais produtos, serviços ou segmentos. Assim, com base nessas sugestões, este estudo contribui não apenas por ter feito uma análise da produção científica na área de ações coletivas, mas, também, contribui com o campo do agronegócio. A partir da demonstração de quais são os modelos aplicados mais estudados, onde eles estão, quais SAGs estão sendo investigados, entre outros aspectos, tem-se um mapeamento de possíveis novas pesquisas a serem realizadas.

Por fim, cabe apontar a principal limitação desta pesquisa, bem como sugestões para estudos futuros. Esta pesquisa limitou-se ao estudo de teses e dissertações no campo da Administração, da Economia e do Planejamento Urbano e Regional. Em vista disso, sugere-se que outras áreas do conhecimento, igualmente interconectadas com a linha de pesquisa de ações coletivas e/ou agronegócio, sejam exploradas, como a Sociologia Rural e as Ciências Agrárias. Além disso, outras fontes de dados podem ser utilizadas para auxiliar na compreensão do cenário da produção científica na temática, a partir de estudos/artigos publicados em periódicos nacionais e internacionais, por exemplo. Ainda, estudos sociométricos que envolvam a existência ou não de redes de autores no campo científico de ações conjuntas no agribusiness seriam, igualmente, profícuos. Enfim, ressalta-se que as contribuições desta pesquisa são mais de cunho teórico do que prático ou empírico, apresentando, principalmente, lacunas passíveis de preenchimento por pesquisadores da área de ações coletivas no agronegócio.

\section{Referências}

ABIC - Associação Brasileira da Indústria do Café. Produção agrícola, 2015. Disponível em: <http:// www.abic.com.br/publique/cgi/cgilua.exe/sys/start. htm?sid=48\#3651>. Acesso em: 15 jan. 2015.

ANTONELLO, C. S. Estudo dos métodos e posicionamento epistemológico na pesquisa de aprendizagem organizacional, competências e gestão do conhecimento. In: XXVI EnANPAD, 2002, Salvador, Anais... Bahia, 2002.

ARAÚJO, C. A. Bibliometria: evolução histórica e questões atuais. Em Questão, Porto Alegre, v. 12, n. 1, p. 11-32, 2006.

AUSTIN, J. E. Parcerias. São Paulo: Futura, 2001.

BIALOSKORSKI NETO, S. Agribusiness cooperativo. In: ZYLBERSZTAJN, D. e NEVES, M. F. Economia e gestão dos negócios agroalimentares: indústria de alimentos, indústria de insumos, produção agropecuária e distribuição. São Paulo: Pioneira, 2000.

BRITO, C. M. Towards an institutional theory of the dynamics of industrial networks. Journal of Business $\mathcal{E}$ Industrial Marketing, v. 16, n. 3, p. 150-166, 2001.

CAPES - Coordenação de Aperfeiçoamento de Pessoal de Nível Superior. Resultados da Avaliação da Capes revelam que pós-graduação teve crescimento de $23 \%$ no triênio, 2014. Disponível em: < http://www.capes.gov. br/36-noticias/6689-resultados-da-avaliacao-da-capesrevelam-que-pos-graduacao-teve-crescimento-de-23no-trienio >. Acesso em: 10 nov. 2014.

CEPEA - Centro de Estudos Avançados em Economia Aplicada. Hortifruti Brasil: o novo mapa da hortifruticultura, 2015b. Disponível em: <http://cepea. esalq.usp.br/imprensa/?page $=340 \& i d=5220>$. Acesso em: 17 jan. 2015.

. PIB Agronegócio - BR, 2015a. Disponível em: $<$ http://cepea.esalq.usp.br/macro/>. Acesso em: 17 jan. 2015.

FERREIRA, N. S. de A. As pesquisas denominadas "estado da arte". Educação \& Sociedade, ano XXIII, n. 79, p. 257-272, 2002.

GRANOVETTER, M. Economic Action and Social Structure: the Problem of Embeddedness. The American Journal of Sociology, New York, v. 91, n. 3, p. 481-510, 1985.

GRANOVETTER, M. The strength of the weak ties. American Journal of Sociology, v. 78, n. 6, p. 1360-1380, 1973. 
IBGE - Instituto Brasileiro de Geografia e Estatística. Produção da Pecuária Municipal, 2013. Disponível em: <http://biblioteca.ibge.gov.br/visualizacao/periodicos/ 84/ppm_2013_v41_br.pdf>. Acesso em: 17 jan. 2015.

IBRAVIN - Instituto Brasileiro do Vinho. Regiões produtoras, 2015. Disponível em: < http://www.ibravin. org.br/regioes-produtoras > . Acesso em: 15 jan. 2015.

MACIAS-CHAPULA, C. A. O papel da informetria e da cienciometria e sua perspectiva nacional e internacional. Ci. Inf., Brasília, v. 27, n. 2, p. 134-140, maio/ago. 1998.

MAIA, G. B. da S., PINTO, A. de R., MARQUES, C. Y. T. e ROITMAN, F. B. e LYRA, D. D. Produção leiteira no Brasil. BNDES setorial, n. 37, p. 371-398. Disponível em: <http://www.bndes.gov.br/SiteBNDES/export/sites/ default/bndes_pt/Galerias/Arquivos/conhecimento/ bnset/set3709.pdf>. Acesso em: 17 jan. 2015.

MÉNARD, C. The economics of hybrid Organizations. Journal of Instituonal and Theoretical Economics, v. 160, n. 3, p. 345-376, 2004.

- e KLEIN, P. G. Organizational issues in the agrifood sector: toward a comparative approach. American Journal of Agricultural Economics, v. 86, n. 3, p. 750-755, 2004.

MINAYO, M. C. de S. O desafio da pesquisa social. In: (Org.) Pesquisa social: teoria, método e criatividade. 29. ed. Petrópolis, RJ: Vozes, 2010.

e SANCHES, O. Quantitativo-qualitativo: oposição ou complementaridade? Caderno de Saúde Pública; Rio de Janeiro, v. 9, n. 3, p. 239-262, jul/set. 1993.

MOMM, C. F. O conhecimento científico em turismo no Brasil: curso de pós-graduação stricto sensu - período de 2000 a 2006. Dissertação (Mestrado) - Programa de Pós-graduação em Ciência da Informação. Universidade Federal de Santa Catarina, 2009.

OCB - Organização das Cooperativas Brasileiras. A força das cooperativas agropecuárias no Brasil, 2014. Disponível em: <http://www.ocbrj.coop.br/HotSite/Noticias/View. aspx?ID=1768> . Acesso em: 15 maio 2014.

- Movimento livre da influência do Estado, 2015. Disponível em: <http://www.ocb.org.br/site/ cooperativismo/evolucao_no_brasil.asp $>$. Acesso em: 8 jan. 2015.

OCEPAR - Organização das Cooperativas do Paraná. Cooperativismo paranaense: desenvolvimento sustentável nocampoenacidade,2015.Disponívelem: <http://www. paranacooperativo.coop.br/ppc/index.php/sistema-oce par/2011-12-05-11-29-42/2011-12-05-11-42-54>. Acesso em: 15 jan. 2015.
OCERGS - Organização das Cooperativas do Rio Grande do Sul. Expressão do cooperativismo gaúcho, 2015. Disponível em: <http:/intranet.sescooprs.coop.br/ arquivos/arqs/20120719102955.pdf $>$. Acesso em: 15 jan. 2015.

OLSON, M. A lógica da ação coletiva: os benefícios públicos e uma teoria dos grupos sociais. São Paulo: Editora da Universidade de São Paulo, 1999.

OSTROM, E. Governing the commons: the evolution of institutions for collective action. EUA: Cambridge University Press, 1990.

- Collective Action and Local Development Processes. Sociologica, Bologna, 2007.

PORTER, M. Competição: estratégias competitivas essenciais. Rio de Janeiro: Campus, 1999.

PRITCHARD, A. Statistical bibliography or bibliometrics? Journal of Documentation, v. 25, n. 4, p. 348-349. 1969.

REDESIST - Rede de Pesquisa em Sistemas e Arranjos Produtivos e Inovativos Locais. Sistemas Produtivos Locais, 2014. Disponível em: <http://redesit.ie.ufrj. br/>. Acesso em: 15 maio 2014.

SANDLER, T. Global Collective Action. Cambridge: University of Southern California, 2004.

SANTOS, A. L. F. dos e AZEVEDO, J. M. L. de. A pósgraduação no Brasil, a pesquisa em educação e os estudos sobre a política educacional: os contornos da constituição de um campo acadêmico. Revista Brasileira de Educação, v. 14, n. 42, p. 534-605, 2009.

SCHMIDT, C. M. et al. Ações coletivas no agronegócio: uma análise do estado da arte a partir dos congressos da SOBER (2004-2013). In: 52º Congresso da Sociedade Brasileira de Economia, Administração e Sociologia Rural, 2014, Goiânia, Anais... Goiás, 2014.

. et al. Collective Actions in Sustainable Rural Tourism: A Case Study of the Western Region of Paraná. Systems Research and Behavioral Science, v. 57/92, p. n/a-n/a, 2015.

SEBRAE - Serviço Brasileiro de Apoio às Micro e Pequenas Empresas. Associação, 2009. Disponível em: <http://bis.sebrae.com.br/GestorRepositorio/ ARQUIVOS_CHRONUS/bds/bds.nsf/DAD2C8C4D5 F6C26B8325766A005102D0/\$File/NT00042C26.pdf >. Acesso em: 15 maio 2014.

SERAPIONI, M. Métodos qualitativos e quantitativos na pesquisa social em saúde: algumas estratégias para a integração. Ciência \& Saúde Coletiva, v. 5, n. 1, p. 187192, 2000. 
SILVANETO, P.Q.et al. Cooperativismo como organismo equalizador da renda. In: $1^{\text {o }}$ Encontro de Estudos sobre Empreendedorismo e Gestão de Pequenas Empresas, 2000, Maringá, Anais... Maringá, 2013.

TEIXEIRA, C. R. O "estado da arte": a concepção de avaliação educacional veiculada na produção acadêmica do Programa de Pós-graduação em Educação: Currículo (1975-2000). Cadernos de Pósgraduação-educação, v. 5, n. 1, p. 59-66, 2006.

ZYLBERSZTAJN, D. Papel dos contratos na coordenação agro-industrial: um olhar além dos mercados. RER, Rio de Janeiro, v. 43, n. 3, p. 385-420, jul./set. 2005.

From Contracts to Networks: New Directions in the Study of Governance of Agro-Food-Energy Networks. In: 4TH European Forum on Systems Dynamics and Innovation in Food Networks, 2010, Innsbruck-Igls, Anais... Innsbruck-Igls, 2010.

.eFARINA, E. Dynamics of network governance: a contribuition to the study of complex forms. Série Working Paper, n. 03/026, São Paulo, 2006. 